\title{
O TEATRO DE MARINA CARR: MANUTENÇÃO E SUBVERSÃO DO CÂNONE IRLANDÊS`
}

\author{
Alinne Balduino Pires Fernandes* \\ Universidade Federal de Santa Catarina
}

Resumo: Neste artigo, apresento ao público brasileiro a dramaturga irlandesa contemporânea Marina Carr (1964-) por meio de uma análise intertextual da peça By the Bog of Cats... (1998) / No Pântano dos Gatos (2017, em tradução minha). A dramaturga, embora reconhecida internacionalmente, é ainda praticamente desconhecida no Brasil. Carr é atualmente um dos nomes mais influentes do teatro irlandês contemporâneo, e é certamente a mulher que alcançou maior reconhecimento na história do teatro irlandês. Demonstrarei os modos como as obras de Carr se inserem no cânone irlandês, mais especificamente por meio de uma análise mais aprofundada de No Pântano. Ao inserir-se no cânone, No Pântano acaba por subverter temas recorrentes da tradição dramática irlandesa por meio do carnavalesco e do grotesco (BAKHTIN, 1998; BOURKE, 2003). Apesar de enraizada em seu contexto originário, a peça utiliza-se de uma "gramática teatral" que ultrapassa as fronteiras nacionais. Palavras-chave: Marina Carr. Cânone irlandês. Manutenção. Subversão.

\section{Introdução: um panorama das obras de Marina Carr}

Neste artigo, apresento ao público brasileiro a dramaturga irlandesa contemporânea Marina Carr, que embora reconhecida internacionalmente, é ainda praticamente desconhecida no Brasil. A dramaturga é atualmente um dos nomes mais influentes do teatro irlandês contemporâneo, e é certamente a mulher que alcançou maior reconhecimento na história do teatro irlandês. Demonstrarei os modos como as obras de Carr se inserem no cânone irlandês, assim como subvertem temas recorrentes da tradição dramática irlandesa. Carr nasceu em 1964, em Offaly, condado localizado numa região denominada de Irish Midlands, área predominantemente rural da Irlanda. As suas peças já conquistaram o status de obras canônicas. Isso fica bastante claro ao constatar que a maior parte das suas peças tiveram suas estréias no Abbey Theatre, o teatro nacional irlandês, fundado em 1904, como o principal

Esta obra está licenciada sob uma Creative Commons - Atribuição 4.0

\footnotetext{
- Os assuntos tratados neste artigo derivam de minha tese de doutorado, não publicada.

* Professora do DLLE/CCE, do PPGI e da PGET. Atualmente é subcoordenadora do Núcleo de Estudos Irlandeses (NEI) da UFSC. Concluiu seu doutorado em dramaturgia e tradução na Queen's University Belfast, Reino Unido, em 2012. Seus trabalhos de pesquisa estão voltados para o teatro escrito por mulheres, com foco no teatro irlandês contemporâneo e estudos comparados entre o teatro brasileiro e teatro anglófono. E-mail: alinne.fernandes@ufsc.br.
} 
marco do "renascimento" dramático irlandês, o Irish Dramatic Revival, movimento liderado por Lady Gregory, W. B. Yeats, Sean O’Casey e John Synge.

Apresento um breve índice das peças que receberam maior cobertura crítica por ordem de ano de produção. A primeira peça da dramaturga a receber uma produção completa foi Low in the Dark, uma peça experimental, cujo texto surgiu de um trabalho colaborativo com os atores sob a forma de devised theatre. Sua estréia deu-se no Project Arts Centre in Dublin, em 1989. Em seguida, Ullaloo teve sua estreia no Peacock Theatre, um dos palcos do Abbey, também em Dublin, em 1991.Foi nos anos noventa que Carr inaugurou o chamado ciclo das peças de "Midlands", arraigadas em cenário tipicamente irlandês e rural cujas histórias giram em torno de questões relativas a famílias disfuncionais. O ciclo tem cinco peças: The Mai (1994), que estreou no palco Peacock do teatro nacional; Portia Coughlan, que estreouno mesmo teatro em 1996; By the Bog of Cats..., que estreou no Abbey, como parte do festival anual de teatro Dublin Theatre Festival, em 1998; On Raftery's Hill, que estreou no Town Hall Theatre em Galway, em 2000; e Ariel, que estreou no Abbey Theatre em Dublin, em 2002 (CARR, 2005; 2009).

Com suas obras já bastante conhecidas fora do circuito irlandês, houve o início de um novo ciclo de produções, com peças de maior teor introspectivo, cujos temas lidam com a morte e apresentam elucubrações sobre sonho e realidade em 2006. Estas peças são: Woman and Scarecrow, que estreou em Londres no Royal Court Jerwood Theatre Upstairs, em 2006; The Cordelia Dream, que estreou no Wilton's Music Hall também em Londres em 2008; Marble, que estreou no Abbey em 2009 (CARR, 2009). Em 2011, estréia a primeira peça de ficção-biográfica sobre uma temática não-irlandesa, a peça 16 Possible Glimpses sobre a vida de Anton Chekhov, que estreou no Peacock, em Dublin. Também em 2011, foi a estréia de Phaedra Backwards, uma adaptação contemporânea do mito de Fedra. Essa foi a primeira das suas peças a estrear fora do circuito Irlanda-Reino Unido, no McCarter Theatre Centre for the Performing Arts em Princeton, EUA. Mais recentemente, em 2015, Carr fez uma adaptação contemporânea da peça Hecuba, de Euripedes, cuja estreia se deu em Stratford-upon-Avon (CARR, 2015). Até o presente momento, a última peça de Carr foi a adaptação irlandesa de Anna Karenina, peça que estreou em dezembro de 2016 no Abbey. ${ }^{1}$

As peças elencadas acima são as que receberam produções completas, tendo sido todas elas publicadas. Desde 1989, a prolífica Marina Carr teve quase 20 peças teatrais publicadas e produzidas. As suas peças publicadas encontram-se tanto em volumes

\footnotetext{
${ }^{1}$ Disponível em: https://www.abbeytheatre.ie/whats_on/event/anna-karenina/. Acesso em: 23/01/2017.
} 
individuais, quanto na coleção "Contemporary Classics" da editora britânica Faber \& Faber, em três volumes até o presente momento, sendo que o último volume foi publicado em 2015.

A título de demonstração da centralidade do trabalho de Carr no teatro contemporâneo irlandês, evidencio aqui como alguns dos recursos dramáticos de Carr se utilizam de obras fundamentais do dito cânone irlandês como seus principais intertextos. Minha discussão será centrada na peça By the Bog of Cats..., traduzida por mim entre $2010 \mathrm{e}$ 2011, a ser publicada no Brasil pela primeira vez em 2017, sob o título No Pântano dos Gatos... De agora em diante, farei referência à peça By the Bog of Cats... utilizando-me de seu título em português.

\section{No Pântano dos Gatos... : manutenção e subversão do cânone irlandês}

Os críticos de Marina Carr a compararam às mais importantes vozes do teatro irlandês, todas elas masculinas com algumas ressalvas, como Yeats, Sean O'Casey, Samuel Beckett, Brian Friel e Frank McGuinness. Essas comparações têm como base o fato de que muito do seu trabalho está estruturado em torno da tradição teatral irlandesa de contar histórias. Melissa Sihra, ao relatar sobre como o trabalho de Carr tem um papel importante de perpetuar o cânone irlandês, comenta que:

\footnotetext{
A tradição teatral irlandesa permanece literária: há uma ênfase contínua na narrativa, no ato de se contar uma história, e na linguagem. Essa ênfase se dá não simplesmente como um modo de comunicar, mas como uma investigação dos processos de construção da memória e da identidade. (SIHRA, 2003, p. 94, tradução minha)
}

Por meio do uso explícito de estruturas clássicas e da tradição folclórica irlandesa, os trabalhos de Carr se utilizam de intertextos presentes tanto na mitologia grega quanto no cânone irlandês. Isso serve para enraizar essas obras no modo tradicional de se fazer teatro na Irlanda, assim como também as tornam transgressoras pelo fato de se utilizarem dessa tradição de modo subversivo. Além disso, o uso de estruturas e mitos clássicos lhes confere uma noção de atemporalidade.

Carr começou a ter seu trabalho reconhecido durante a "Era do Tigre Celta" (The Celtic Tiger Era), período que corresponde aos anos de 1990 a 2005 (LONERGAN, 2010). A "Era do Tigre Celta" diz respeito ao rápido e intenso crescimento econômico da Irlanda entre 1993 e 2002, seguido de uma baixa entre 2001 e 2002, quando a Irlanda se viu profundamente afetada pelo inchaço e subsequente explosão da grande bolha do mercado imobiliário. É nesse contexto que os temas das peças de Carr ecoam, mesmo que subversivamente, o projeto de Yeats de que as representações do povo irlandês fossem refletidas pelas lentes do folclore e do 
mito no palco nacional. Carr contesta esse "reflexo" usando formas dramáticas tradicionais com conteúdo subversivo, o que confronta essa noção de Yeats, assim como também as ideias que forjaram os princípios de fundamentação cultural do teatro irlandês.

Para fazer uma breve contextualização dos fundamentos do teatro irlandês idealizados por Yeats e do Abbey, como teatro nacional, cito Mark Phelan (2009, p. 136, tradução minha), ao dizer que:

[O] renascimento dramático foi um assunto cultural e político de dimensões amplas que buscou descrever e definir uma cultura e identidade irlandesa autêntica e autônoma. Nesse período, o oeste da Irlanda e seus camponeses foram idealizados por meio de uma retórica nacionalista, o que reverteu (e ironicamente replicou) o processo pelo qual a Irlanda foi orientalizada no discurso imperial britânico.

As peças de Carr, especialmente as do Ciclo de Midlands, tem como cenário principal uma Irlanda rural, que num primeiro momento, remete seus espectadores à Irlanda do "renascimento" dramático irlandês, que tem como protagonista o camponês e seu modo simples de vida. Esse camponês representa o irlandês "autêntico", segundo o projeto nacionalista do final do século XIX. Carr conserva suas peças num cenário rural, mas diferentemente das peças fundadoras do cânone, as coloca em terras inférteis onde a família, ao contrário de um núcleo idealizado, é a fonte da corrupção humana e da vida em sociedade.

Em entrevista concedida à Mária Kurdi, Carr se refere a como escritores conscientemente se situam dentro das tradições literárias e dramáticas e afirma que o(a) "escritor(a) é uma pega. Você usa o que precisa. Toda a história da escrita gira em torno de tomar emprestado da geração anterior" (KURDI, 2003, p. 94, tradução minha). Vale a explicação de que "pega", magpie em inglês, é um pássaro da família do corvo, famoso por roubar coisas brilhantes. Ao deliberadamente "tomar emprestado da geração anterior", Carr demonstra ter consciência de que as tradições - sempre "inventadas", já diria Hobsbawn (1992) - funcionam como criadores de identidade que moldaram e continuam a moldar o senso de pertencimento e não-pertencimento das várias comunidades irlandesas. Nesse processo de encontrar a sua própria voz como escritora, Carr tanto aprendeu a escrever para o teatro a partir de elementos tradicionais, quanto os subverteu.

A peça No Pântano dos Gatos... do ciclo de Midlands é um exemplo de manutenção e transgressão do cânone. No Pântano é uma peça sobre Hester, uma mulher da minoria étnica nômade Irish traveller (viajante irlandês, em tradução literal). Carthage, seu parceiro de nove anos a deixa por uma mulher mais jovem e mais rica, chamada Caroline, que é filha de um proprietário de terras. Hester é apelidada pelas outras personagens de tinker, termo pejorativamente usado em referência a viajantes, ciganos e outros grupos nômades, 
especialmente na Irlanda e no Reino Unido. A história de abandonos de Hester começa aos sete anos de idade, quando sua mãe desaparece. Hester teme que a história se repita com a sua própria filha Josie por conta das ameaças de Carthage de levar a criança embora para dar-lhe uma vida melhor, longe de Hester. Em resumo, a história de Hester é sobre o dilema do pertencimento, na qual as suas raízes étnicas são a causa do preconceito que se instala entre aqueles com os quais Hester tenta comungar. A peça utiliza-se de figuras de estilo presentes em um número expressivo de obras do cânone irlandês. De forma bastante consciente, reelabora muitos dos temas e tradições dessas obras. Mas é claro que, pensando-se em uma produção da peça no Brasil, uma das perguntas que ficam latentes é que implicações isso traz para o tradutor e produtor da peça no Brasil? A tradução de No Pântano para o público brasileiro certamente cria uma teia diferente de intertextos daquela do seu contexto originário.

No Pântano é frequentemente comparada à peça Playboy of the Western World, de John Synge ([1907] 2009), obra parte do movimento de renascimento dramático. As duas peças lidam com "a necessidade crítica da auto-definição" (SIHRA, 2000, p. 259). Ambos protagonistas, no caso de Playboy, Christy Mahon, e em No Pântano, Hester, estão numa constante busca pelas suas próprias histórias para conseguirem entender e construir a si mesmos e o seu passado. No caso de No Pântano, Hester é uma selvagem aos olhos da comunidade, assim como Christy em Playboy, é também um "estranho dentro de casa", um tema tradicional que assombra a imaginação dos espectadores da peça em sua cultura originária. Num país essencialmente branco e católico e onde a noção de nacionalismo é tão amplamente aceita parece haver pouco para ser contestado e, por isso, ser algo ou em acreditar em algo diferente disso torna-se extremamente difícil (GRENE, 1999, p. 52).

O uso da narração, que funciona como uma "contação" de história dentro da peça, fornece ao público perspectivas diversas, assim como o faz a peça, Philadelphia, Here I Come! ([1964] 1994)² de Brian Friel, traduzida como "Filadélfia, lá vou eu!" por Domingos Nunez, diretor e fundador da companhia paulista teatral Cia Ludens. Em No Pântano, cada uma das personagens conta uma versão diferente da história da mãe de Hester, recurso também presente em Philadelphia. Nesse aspecto, o recurso da narração confere às peças um meio de desestabilizar identidades por meio de narrativas opostas (SIHRA, 2000, p. 258), criadas a partir de memórias subjetivas. Em Philadelphia, por exemplo, o protagonista Gareth é interpretado por duas personagens, o "público" e o "privado". Suas reminiscências são confrontadas pelas do pai, um homem com o qual Gareth nunca teve uma relação próxima.

\footnotetext{
${ }^{2}$ Sempre que o ano aparecer entre colchetes, refiro-me ao ano da primeira produção da peça.
} 
Essas narrativas contraditórias servem como um símbolo para a natureza quimérica da memória. Esse questionamento da história funciona como um recurso meta-teatral, relevante inclusive para se pensar em como traduzimos peças para serem encenadas e nos modos como a tradução pode envolver o novo público-alvo permitindo que os espectadores revisitem as suas próprias histórias a partir de uma nova perspectiva.

Além disso, a figura central, porém ausente de No Pântano, é a mãe de Hester, Josie Swane, que aparece na lista de personagens como uma voz, que nós, leitores e espectadores nunca escutamos. Essa personagem ausente é perturbadora e personifica uma espécie de "pátria mãe", que também é tema recorrente no teatro irlandês e que nos remete o renascimento dramático irlandês do começo do século XX. A peça Cathleen Ni Houlihan ([1902] 2007), de Yeats e Lady Gregory, tem como personagem central uma mulher velha (e jovem ao mesmo tempo) que metaforicamente representa a nação. O seu destino, no contexto da peça, é vagar por conta de seu passado conturbado. Tanto as personagens de Yeats e Lady Gregory, quanto as de Marina Carr, se utilizam de canções como recursos de fabricação de memória. Em No Pântano, por exemplo, Josie Swane é lembrada pela Mulher-Gato como uma "seresteira", em inglês uma song stitcher, que fazia músicas a partir de histórias que ela escutava e experiências vividas. De modo semelhante, a Cathleen de Yeats e Lady Gregory, uma mulher mitológica, canta sobre um homem que um dia amou e que morreu por amor a ela. Essa figura maternal ausente e misteriosa ressoaria também num contexto brasileiro?

Em Cathleen, a figura romantizada da nação sofredora debaixo do crivo dos britânicos é representada por uma andarilha misteriosa, por quem Michael deixa a sua jovem noiva Delia - nessa peça, a beleza da mártir profética e idealizada está nos olhos de quem vê. Pensando-se no contexto irlandês, esse tipo de representação pública da mulher no começo do século XX, não se restringe somente ao âmbito das produções teatrais, mas é também amplamente presente também nos discursos políticos e políticas culturais de fundação da nação irlandesa independente. Para exemplificar isso, Éamon de Valera, uma das figuras políticas-chave na rebelião irlandesa de 1916 (The Easter Rising), foi o principal idealizador da constituição irlandesa atualmente em vigor desde 1937 e terceiro presidente da Irlanda entre os anos de 1959 e 1973. Na nova constituição de 1937, no capítulo sobre a família, afirma-se que: "Em particular, o Estado reconhece que, por dedicar a sua vida ao lar, a mulher dá ao Estado suporte sem o qual o bem comum não poderá ser alcançado." (tradução minha) ${ }^{3}$ Esses discursos fomentaram uma espécie de ingenuidade que reforçou a imagem de mulheres

\footnotetext{
3 "In particular, the State recognises that by her life within the home, woman gives to the State a support without which the common good cannot be achieved." (Constitution of Ireland, art. 41, para. 2).
}

Anu. Lit., Florianópolis, v. 23, n. 1, p. 31-43, 2018. ISSNe 2175-7917 
como modelos de idealismo e generosidade (LEENEY, 2007, p. 24).

\section{Subversão pelo grotesco e o carnavalesco}

Além das relações existentes entre a peça e seus pares irlandeses canônicos, No Pântano subverte e faz combinações de características grotescas e carnavalescas por unir rituais religiosos e pagãos assim como por reverter os seus papeis sociais e as suas funções (BOURKE 2003). Ao adotar-se uma perspectiva do "senso carnavalesco do mundo" de Bakhtin (1998, tradução minha do inglês), e aqui, mais especificamente, das meta-encenações presentes em No Pântano, a peça pode ser interpretada como um ritual de passagem.

Uma grande mudança está prestes a acontecer no Pântano dos Gatos: o casamento de Caroline, a filha do abastado fazendeiro, e Carthage, ex-parceiro de Hester, o que dará início a uma nova era no Pântano. No entanto, essa mudança só poderá ocorrer com o sacrifício do "louco", que é Hester, o que ecoa os rituais medievais. Bakhtin, ao investigar os processos envolvidos no carnaval, desenvolveu a noção de "atos carnavalescos", que consistem numa série de ações cíclicas. Central à paródia e ao escárnio do carnaval é também o uso de formas grotescas, que abundam em No Pântano. Há uma predominância de emoções viscerais em detrimento da razão e da sensatez, na qual o corpo é representado como algo selvagem, cheio de paixões e desejos primitivos (BOURKE, 2003, p. 131). Isso pode ser visto na profunda conexão que Hester tem com a natureza, que é o seu local de nascimento, o pântano, como parte também do ciclo carnavalesco de renovação: Hester veio do pântano e ao pântano retornará. A terra funciona tanto como ventre quanto como túmulo.

Para Bakhtin, "o carnaval celebra a mudança em sim. Ele consiste na celebração do processo de se substituir e não no que está sendo substituído. [...] O carnaval não torna nada absoluto, mas exalta a alegria da relatividade de todas as coisas.” (1998, p. 252, tradução minha do inglês). A leitura de No Pântano a partir de uma perspectiva carnavalesca torna evidente a meta-teatralidade da peça: os seus personagens vivem e encenam duas vidas, suas vidas antes e depois do casamento no Segundo Ato, quando a mãe, ex-parceira, filha e noiva de Carthage aparecem, transformam-se em noivas ao aparecerem no palco vestidas de branco e seus papeis são, portanto, revertidos, com a exceção da própria noiva:

DONA KILBRIDE: Ela é um desastre, isso é o que ela é, aparece aqui com o vestido da Primeira Comunhão, fazendo um papelão na frente de todo mundo. CARTHAGE: Quem 'tá fazendo um papelão com esse vestido ridículo é a senhora. DONA KILBRIDE: O quê? Não estou! É assim que tu me agradeces. Me esforço pra me vestir o melhor possível. (Quase chorando) Economizei tudo o que eu tinha pra comprar esse vestido. Como é que eu ia saber que a noiva 'taria de branco também. (CARR, 2017, p. 103). 
E o público vê a chegada da última "noiva" com a entrada de Hester, ainda no Segundo Ato, sinalizada pela rubrica: "Entra Hester vestida de noiva com sapatos, véu, penteado e maquiagem de casamento." (CARR, 2017, p. 108)

Também no Segundo Ato, Mulher-Gato, uma vidente pagã, entra em cena de braços dados com o padre que celebrará o casamento, Padre Willow. As duas personagens grotescas fazem planos de férias juntos e implicam um com outro por conta de seus hábitos alimentares. O absurdo da cena torna-se ainda mais claro quando Dona Kilbride, a mãe do noivo, pede que o Padre abençoe o alimento, mas o Padre então decide revelar que um dia ele teve uma noiva:

PADRE WILLOW: Em nome do Pai, do Filho e do Espírito Santo, isso pode ou não ser uma surpresa pra vocês, mas quase fui noivo uma vez. O seu nome era Elizabeth Kennedy, não, esse era o nome da minha mãe, o seu nome era - espera, está vindo, bom, não era pra ser, no fim, nós brigamos por causa de um ovo de pato nas férias enquanto caminhávamos à beira do rio Shannon, afinal de contas, qual era o nome dela? Helen? Não.

DONA KILBRIDE: O senhor poderia fazer uma oração, Padre Willow, e seja PADRE WILLOW: A oração, sim. Como é que se faz mesmo?

DONA KILBRIDE: Abençoai, Senhor, os alimentos que vamos tomar; que eles reno

PADRE WILLOW: Rowena. Era isso. Rowena Phelan. Eu não devia ter comido aquele ovo de pato - não-(Fica ali em desalento.) (CARR, 2017, p. 108).

Os noivos pedem ainda que Mulher-Gato os abençoe e preveja o que o futuro reserva para eles: "CARTHAGE: Agora, Mulher-Gato, 'benção pra mim e pra Caroline./ MULHERGATO: Já que insistes. Lápides separadas. Sinto muito, mas pedi pra vocês não perguntarem." (CARR, 2017, p. 102) Essa representação de sincretismo reflete, mais uma vez, os atos medievais de carnaval, conforme descritos por Bakhtin, o que também serve como um resgate e uma paródia da encenação de uma Irlanda pré-Cristianismo e a sua conversão ao catolicismo no século V, como narram lendas irlandesas, como "Os filhos de Lir" (The Children of Lir), na qual os filhos do Rei Lir são amaldiçoados pela nova e ciumenta esposa do Rei, Aoife, e são transformados em cisnes até que aceitem se converter ao cristianismo (O'FARREL, 1995).

Esse sincretismo presente em No Pântano também traz implicações para a tradução da peça e uma produção no Brasil em potencial, no que tange a cumplicidade e o engajamento do público. As demonstrações de "blasfêmia" da Mulher-Gato e do Padre Willow também podem funcionar como figuras que assombram a memória do público brasileiro. $\mathrm{O}$ sincretismo religioso tem sido parte da história brasileira desde o século XVI, na tentativa dos portugueses de evangelizar os povos indígenas deste território e os escravos africanos importados como mercadoria e mão-de-obra como parte do comércio português. Uma das 
formas mais comuns de sincretismo entre as comunidades afro-brasileiras é, o que por um longo período de tempo foi visto como uma mistura de rituais africanos e católicos, o candomblé, apesar de argumentar-se que o Candomblé seja uma religião por si só (ILÉ AXÉ OPÔ AFONJÁ, 1999). O Candomblé possui características sincréticas que começaram a ser desenvolvidas no século XVI até o começo do século XX, como uma forma de resistência à autarquia portuguesa. Essa noção de que o Brasil, assim como a Irlanda, tem um passado colonial e, portanto, formas combinadas de práticas culturais, as quais muitas vezes são usadas como uma forma de resistência à imposição do colonizador, demonstram que essa subversão dos valores culturais dominantes na peça pode também falar diretamente com o público brasileiro.

\section{Relações com o clássico e possíveis relações com o repertório brasileiro}

No Pâtano, diferentemente de Cathleen, utiliza de um modo subversivo um tema tradicionalmente consagrado como a grande causa nacionalista (a luta da Irlanda pela independência) e questiona, de modo paródico, a Irlanda idílica e tão desejada. As figuras maternas em Carr são forças destrutivas, tanto para elas mesmas quanto para outros. Em No Pântano, a primeira figura materna é Josie, que abandona Hester. Hester, por sua vez, ao ser mandada embora do pântano onde reside, põe fogo em todos os novilhos do seu ex-parceiro e pai de sua filha e, quando prestes a se matar, é interrompida pela filha que diz querer ser levada com junto ela. Hester então, em um só golpe, mata a filha e, em seguida, suicida-se. Pode esse aspecto da peça ter um impacto similar com um público brasileiro? A maternidade em No Pântano é representada como algo transgressivo e destruidor e não como energia que dá vida.

Como venho argumentando, a peça não só lida com temas recorrentes do teatro irlandês, questões sócio-políticas do presente e do passado do país, mas também questiona os papeis sociais pré-estabelecidos, como o da função primordial da mulher na sociedade. No Pântano é uma versão moderna da Medeia de Eurípedes, que adotou a forma clássica para gerar efeitos tragicômicos. Isso está presente na peça logo na sua cena de abertura, quando a morte de Hester é anunciada por um ceifador que chega cedo demais. A personagem da morte, personificada na figura de um homem elegante, erra o horário da partida de Hester, por confundir o alvorecer com o crepúsculo:

HESTER: [...] Mas e tu, espreitador de alma, que alma tu veio roubar?

AQUELE QUE ESPREITA ALMAS: Vim roubar a alma de uma mulher chamada Hester Swane.

HESTER: Mas eu sou a Hester Swane. 
AQUELE QUE ESPREITA ALMAS: Não pode ser você. Você está viva.

HESTER: É, 'tou mesmo e assim vou continuar.

AQUELE QUE ESPREITA ALMAS: (olha em volta, confuso) Agora é o nascer ou o pôr do sol?

HESTER: O que tu tem com isso?

AQUELE QUE ESPREITA ALMAS: Por obséquio.

HESTER: Poderia ser tanto nascer quanto pôr do sol. A luz é muito parecida. Mas agora é o nascer do sol, olha ele vindo lá.

AQUELE QUE ESPREITA ALMAS: Pois então, acho que cheguei cedo demais. Confundi o alvorecer com o entardecer. Mil perdões. (CARR, 2017, p. 16).

Ao trazer a peça para o Brasil, assim como qualquer outra obra de Carr, é inevitável não pensar nas relações que a obra trava com o imaginário brasileiro. A recepção de uma obra de arte ampara-se numa negociação entre o estranho e o familiar, o que é estrangeiro e o que é doméstico. No Pântano, ao mesmo tempo que arraigada em seu contexto irlandês, pode ser vista como uma peça que fala para além de suas fronteiras nacionais. A Medeia de Eurípides já foi inclusive reescrita no teatro brasileiro. Gota d'Água: Uma Tragédia Brasileira (1975), de Paulo Pontes e Chico Buarque, foi escrita como parte do movimento artístico Teatro de Resistência em resposta à ditadura militar brasileira nos anos de 1964 a $1985 .{ }^{4}$

Como aponta Mesquita (2009), No Pântano, assim como Gota d'Água, lidam com problemas contemporâneos com uma "lente atemporal". No Pântano, utiliza-se do realismo fantástico, no qual mortos e vivos coexistem e alguns vivos são capazes de se comunicar com os fantasmas que surgem. Além disso, No Pântano lida com diversos problemas sociais, como as consequências do desejo por terra, acúmulo por propriedades e a marginalização das minorias. Num contexto diferente, porém de forma similar, Gota d'Água denuncia os abusos cometidos por Creonte, um proprietário de terras que muito lucra por explorar os pobres. De um modo semelhante, apesar de num contexto geográfico e cultural diferente, a peça brasileira centraliza indivíduos marginalizados ao protagonizar a vida de personagens da periferia do Rio de Janeiro. O propósito da peça é expor as condições precárias da vida dos habitantes pobres de uma favela, assim lidando com natureza avarenta do capitalismo. Ambas as peças, no entanto, são respectivamente enraizadas na sua "brasilidade" e na sua "Irishness", por trazerem para a cena problemas locais; ambas as peças trazem uma visão central da periferia por posicionar personagens marginalizados como protagonistas.

Embora a peça faça uso de referências específicas e arraigadas em sua cultura originária, a peça tem uma estrutura que se estende para conotações mais amplas e transcende esse enraizamento no local. Por outro lado, essa mesma estrutura pode proporcionar ao seu público brasileiro uma "nova memória experienciada" (CARLSON, 2011, p. 6, tradução

\footnotetext{
${ }^{4}$ Para mais informações sobre o assunto, vide o verbete "Teatro de Resistência" na Enciclopédia Itaú Cultural. Disponível em: http://enciclopedia.itaucultural.org.br/termo613/teatro-de-resistencia. Acesso em: 20/01/2017.
} 
minha) como um meio de trazer à tona aquilo que é diferente e novo em No Pântano em contraposição com o que já é conhecido para espectadores brasileiros em potencial. Como a memória é tão essencial para a recepção de uma obra, No Pântano, em sua tradução para o português do Brasil, ao aceitar os desafios em cada produção da peça irlandesa no Brasil, certamente adquirirá uma voz brasileira.

\section{Conclusão}

Com esse breve panorama, espero ter demonstrado como Marina Carr posiciona-se no cânone irlandês e como suas obras, mais especificamente, No Pântano dos Gatos.../By the Bog of Cats..., fazem uma manutenção desse cânone e subvertem temas recorrentes, figuras de estilo e de linguagem ao se utilizarem do grotesco e do carnavalesco. Além disso, No Pântano, cujo principal intertexto é Medeia de Eurípides, apresenta uma "gramática teatral" que transcende as práticas teatrais tradicionalmente irlandesas.

\section{Referências}

BAKHTIN, Mikhail. Carnival and the Carnivalesque. In: STORY, John (Ed.). Cultural Theory and Popular Culture: A Reader. 2. ed. London/ New York/ Toronto/ Sydney/ Paris: Prentice Hall, 1998, p. 250-259.

BOURKE, Bernadette. Carr's 'Cut-Throats and Gargoyles': Grotesque and Carnivalesque Elements in By the Bog of Cats... In: LEENEY, Cathy; MCMULLAN, Anna (Ed.). The Theatre of Marina Carr: "Before Rules Was Made". Dublin: Carysfort Press, 2003, p. 128144.

BUARQUE, Chico; PONTES, Paulo. Gota d'Água: Uma Tragédia Brasileira. Rio de Janeiro: Civilização Brasileira, 2004.

CARLSON, Marvin A. The Haunted Stage: Theatre as Memory Machine. 5. ed. Ann Arbor: The University of Michigan Press, 2011.

CARR, Marina. Marina Carr: Plays 1 - Low in the Dark, The Mai, Portia Coughlan, By the Bog of Cats... London: Faber and Faber, 2005.

Marina Carr: Plays 2 - On Raftery's Hill, Ariel, Woman and Scarecrow, The Cordelia Dream, Marble. London: Faber and Faber, 2009.

. Marina Carr: Plays 3 - Sixteen Possible Glimpses; Phaedra Backwards; the Map of Argentina; Hecuba; Indigo. London: Faber and Faber, 2015. Editor, 2017.

No Pântano dos Gatos... Trad. de Alinne Fernandes. São Paulo: Rafael Copetti

Constitution of Ireland, 1937. Irish Statute Book, Dublin, out. 2015. Disponível em: $<$ http://www.irishstatutebook.ie/eli/cons/en/html>. Acesso em: 20 jan. 2017. 
FRIEL, Brian. Philadelphia, Here I Come!: A Comedy in Three Acts. London: Faber and Faber, 1994.

GRENE, Nicholas. Politics of Irish Drama: Plays in Context from Boucicault to Friel. Cambridge: Cambridge University Press, 1999.

HOBSBAWM, Eric. The Invention of Tradition. HOBSBAWM, Eric; RANGER, Terence (Ed.). Cambridge: Cambridge University Press, 1992.

ILÉ AXÉ OPÔ AFONJÁ, Iansã is not Saint Barbara. In: LEVINE, Robert M.; CROCITTI, John J. (Ed.). The Brazil Reader: History, Culture, Politics. Durham: Duke University Press, 1999. p. 408-410.

KURDI, Maria. I was tired of the sentimental portrayal of mothers: A Talk with Irish Playwright Marina Carr. Modern Filológiai Közlemények, Miskolc, v. 5, n. 2, p. 94-100, 2003.

LEENEY, Cathy. Interchapter I: 1900-1939. In: SIHRA, Melissa (Ed.). Women in Irish Drama: A Century of Authorship and Representation, Hampshire: Palgrave Macmillan, 2007, p. 23-27.

LONERGAN, Pstrick. Theatre and Globalization: Irish Drama in the Celtic Tiger Era. Nova York: Palgrave Macmillan, 2010.

MESQUITA, Zoraide R. C. de. Two Contemporary Medeas. Irish Migration Studies in Latin America, Smoorbeg, v. 7, n. 2, p. 195-203, 2009. Disponível em: http://www.irlandeses.org/0907carrasco.htm. Acesso em: 11/11/2017.

O‘FARRELL, Padraic. Ancient Irish Legends. Dublin: Gill and Macmillan Ltd, 1995.

PHELAN, Mark. 'Authentic Reproductions': Staging the 'Wild West' in Modern Irish Drama. Theatre Journal, Baltimore, v. 61, n.2, p. 235-248, 2009.

SIHRA, Melissa. A Cautionary Tale: Marina Carr's By the Bog of Cats. In: JORDAN, Eamonn (Ed.). Theatre Stuff: Critical Essays on Contemporary Irish Theatre. Dublin: Carysfort Press Book, 2000, p. 257-268.

. Reflections Across Water: New Stages of Performing Carr. In: LEENEY, Cathy; MCMULLAN, Anna (Ed.). The Theatre of Marina Carr: "Before Rules Was Made”. Dublin: Carysfort Press, 2003, p. 92-113.

Teatro de Resistência. In: Enciclopédia Itaú Cultural. Disponível em: http://enciclopedia.itaucultural.org.br/termo613/teatro-de-resistencia. Acesso em: 19/01/2017.

SYNGE, John M. Playboy of the Western World. In: SADDLEMYER, Ann (Ed.). The Playboy of the Western World and Other Plays: Riders to the Sea; The Shadow of the Glen; The Tinker's Wedding; The Well of the Saints; The Playboy of the Western World; Deirdre of the Sorrows. Oxford: Oxford University Press, 2009, p. 95-146.

YEATS, W. B.; GREGORY, Lady. Collaborative One-Act Plays, 1901-1903 ("Cathleen ni Houlihan," "The Pot of Broth," "The Country of the Young," "Heads or Harps"): Manuscript Materials. PETHICA, James (Ed.). Ithaca: Cornell University Press, 2007. 
The Theatre of Marina Carr: Maintenance and subversion of the Irish canon

Abstract: In this article, I aim to introduce the contemporary Irish playwright Marina Carr (1964-) to the Brazilian public by means of an intertextual analysis of By the Bog of Cats... (1998) / No Pântano dos Gatos (2017, my translation). Carr, who is internationally known and is currently the most influent female playwright in Ireland, is still practically unknown to Brazilian audiences. Here I will demonstrate the ways By the Bog of Cats... is inserted in the Irish canon. As part of the Irish canon, By the Bog of Cats... subverts some of the recurrent themes and tropes present in the Irish dramatic tradition through the carnivalesque and the grotesque (BAKHTIN 1998; BOURKE 2003). In addition to this analysis, I will investigate ways in which the Brazilian public may relate to the play, should the play be produced in Brazil. Although By the Bog of Cats... is deeply rooted in its originary Irish context, the play uses a "theatrical grammar" that goes beyond national borders.

Keywords: Marina Carr. Irish canon. Maintenance. Subversion.

Recebido em: 13/04/2017

Aceito em: 24/10/2017

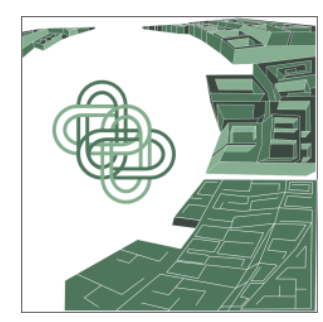

